\title{
A pandemia de COVID-19: uma crise sanitária e humanitária
}

\author{
COVID-19 pandemic: a health and humanitarian \\ crisis
}

\author{
La pandemia de COVID-19: una crisis sanitaria \\ y humanitaria
}

\author{
Nísia Trindade Lima 1 \\ Paulo Marchiori Buss 1 \\ Rômulo Paes-Sousa 2
}

doi: 10.1590/0102-311X00177020
Em 2020, a pandemia da COVID-19 tem levado quase todo o planeta a uma crise sanitária e humanitária, testando a espécie humana em várias dimensões. A pergunta que se eleva sobre tantas dúvidas é: seria ela um fenômeno inevitável diante da relação que os humanos mantêm com os diversos ecossistemas e as demais espécies animais e vegetais? Ou em uma abordagem simplificada, o desfecho episódico - porém recorrente - da forma como se produz e se consome bens e serviços no mundo?

A pandemia magnifica as tensões dilacerantes da organização social do nosso tempo: globalizada nas trocas econômicas, mas enfraquecida como projeto político global, interconectada digitalmente porém impregnada de desinformação, à beira de colapso ambiental, mas dominantemente não sustentável, carente de ideais políticos, mas tão avessa à política e a projetos comuns. A pandemia nos coloca diante do espelho, que nos revela um mundo atravessado por muitas crises e carente de mudanças.

Em 1993, Richard Krause constatou a persistência das doenças infecciosas que, em sua visão, representavam uma ameaça permanente a todos os países, independentemente do grau de desenvolvimento econômico e condições sanitárias. Para ele, "as epidemias são tão certas como a morte e os impostos" 1 (p. xvii). Pouco antes do impacto da epidemia de aids, perspectivas como a do citado virologista americano já colocavam em xeque uma das teses dominantes na saúde pública da segunda metade do século XX, caracterizada pelo prognóstico da eliminação das doenças decorrentes da afluência e da urbanização. Dessa forma, muitas doenças poderiam ser prevenidas pelos avanços tecnológicos, universalização do saneamento básico e, particularmente, pelo desenvolvimento de antibióticos e vacinas. Nesse modelo teórico, ocorreria a perda de importância das doenças infeciosas nos países mais ricos, onde as doenças dos períodos de carência cederiam inexoravelmente lugar para as doenças da abundância e do excesso. Contudo, em muitos países permaneceria uma distribuição desigual nos padrões epidemiológicos, indicando que a prevalência de doenças infeciosas, da desnutrição e, mesmo, da baixa expectativa de vida, seria inversamente proporcional ao tamanho da economia dos países. No mundo, a desigualdade na distribuição dos padrões epidemiológicos seria em função da distribuição desigual das condições socioeconômicas e dos meios de prevenção e tratamento de doenças.

A pandemia de COVID-19 evidenciou uma profunda mudança nas relações entre espaço, tempo e doenças infecciosas. Percebeu-se que o mundo estava mais vulnerável à ocorrência e à disseminação global, tanto de doenças conhecidas, como novas. A integração das economias em todo o planeta permitiu: um grande aumento de circulação de pessoas e de mercadorias; promoveu o uso intensivo
1 Fundação Oswaldo Cruz, Rio de Janeiro, Brasil. 2 Instituto René Rachou, Fundação Oswaldo Cruz, Belo Horizonte, Brasil.

\section{Correspondência} R. Paes-Sousa Instituto René Rachou, Fundação Oswaldo Cruz. Rua Uberaba 780, sala 5C sub-solo, Belo Horizonte, $M G$ 30180-080, Brasil. romulo.paes@fiocruz.br 
e não sustentável dos recursos naturais; e acentuou mudanças sociais favoráveis ao contágio das doenças infeciosas, p.ex., adensamento populacional urbano, massiva mobilidade de populações nestes espaços, agregação de grandes contingentes de pessoas pobres, que por seu turno acabariam por ocupar habitações precárias com acesso limitado ao saneamento básico. Essas condições permitiram o desenvolvimento da "globalização da doença" como a COVID-19, tomando aqui de empréstimo a definição de Fidler 2 relativa à pandemia de síndrome respiratória aguda grave (SARS), que ocorreu em 2002-2003.

\section{Nêmesis e o desafio das novas epidemias}

Mas seriam as pandemias fatalidades? Vitórias de Nêmesis, a deusa grega da vingança, tal como nos lembra Philip Roth 3 em seu romance sobre as relações entre a epidemia de poliomielite e a II Guerra Mundial nos Estados Unidos? Recolocamos aqui a pergunta formulada no início deste artigo. Para respondê-la temos de considerar as epidemias e, sobretudo, pandemias como a que vivemos como um fenômeno multidimensional, a um só tempo, biológico, ambiental e social, com fortes implicações econômica e política. Tanto a disseminação acelerada da doença pelo mundo e seus efeitos colaterais, como as estratégias de respostas às crises sanitária e humanitária, indicam uma sobreposição de tempos e lugares na experiência humana de enfrentar poderosos choques.

Nesse contexto, observa-se o retorno de práticas inadequadas sobejamente registradas em textos científicos e literários: negação da gravidade do quadro, promessas tecnológicas irrealizáveis, cultura do medo, misticismo da imunidade e da cura, mercantilização do cuidado, exortação por um evitável sacrifício alheio, inépcia na gestão dos meios de combate disponíveis, que nos levam a todos a um desnecessário sofrimento.

Também, as respostas sociais organizadas contêm aspectos cumulativos do que fomos aprendendo no enfrentamento das doenças. $\mathrm{O}$ aparato utilizado para o combate à pandemia tem combinado tecnologias desenvolvidas em diferentes períodos históricos. Medidas quarentenárias foram consolidadas no século XIV, nas cidades portuárias do Mediterrâneo, como estratégia de controle da peste negra. Hospitais modernos e drogas antivirais que são legados do século XX. Essas tecnologias são agregadas a um aparato contemporâneo desenvolvido a partir do final do século passado, como: reverse transcription polymerase chain reaction (RT-PCR), smartphones, biotecnologia genômica, big data, inteligência artificial, câmeras de monitoramento, geolocalização, drones e telemedicina. Esse conjunto de soluções tem sido utilizado em alguma medida pelos 181 países atingidos pela doença de acordo com sua disponibilidade. A cobertura e intensidade do uso dessas tecnologias pelos países indicam que a capacidade industrial, o volume de riqueza, a adaptabilidade social e a capacidade de gestão política, são os ativos mais importantes a serem mobilizados diante de choques globais de múltiplas dimensões. De certa forma, são sensíveis indicadores de como estão distribuídas as capacidades econômicas e de gestão no nosso planeta.

Como em todas as crises, cada país tende a mobilizar seus melhores ativos para lidar com o problema. Obviamente, nesse percurso, suas fraquezas também são evidenciadas. Portanto, é no confronto dessas forças antagônicas que vidas são ganhas ou inutilmente perdidas.

Os países industrializados da Ásia enfrentaram a pandemia com uma excepcional mobilização de recursos físicos e tecnológicos. Também mobilizaram pessoal capacitado e imobilizaram grandes contingentes populacionais, impondo várias modalidades de isolamento social. Seja por imposição, seja por adesão, na China (incluindo Hong Kong), Japão, Taiwan e Coreia do Sul, diversos tipos de restrição da mobilidade foram implantados, em geral com o uso intensivo de tecnologias. Contando com recursos mais modestos, Vietnã e Tailândia (além da Costa Rica nas Américas) também conseguiram conter os avanços da pandemia em seus respectivos países.

Após a Ásia, o epicentro da pandemia se deslocou para a Europa. Em tese, esse seria o melhor território para se combater o vírus: o continente mais homogêneo em termos econômicos e sociais do planeta (ainda que muito diverso em relação à cultura); o berço da revolução industrial, dos sistemas nacionais de saúde e dos modelos de proteção social; um espaço densamente povoado por pessoal altamente qualificado e com o melhor sistema rodoferroviário do planeta. Itália, Reino Unido, Espanha e França enfrentaram grandes dificuldades no combate à doença, com surpreendentes números 
de mortes. Em seguida, o epicentro da pandemia se deslocou para os Estados Unidos, que, embora seja muito mais desigual que os países europeus, tem a maior economia do planeta e grande concentração de recursos para enfrentar choques do porte que é a COVID-19. A última edição do Global Health Security Index 4 classificou os Estados Unidos e o Reino Unido como os países mais preparados dentre os pesquisados para enfrentar a emergência de crises sanitárias. Na mesma edição, Nova Zelândia e China ocupavam posições mais modestas no ranking, respectivamente 35a e 51a posições. Contudo, várias nações que acumularam competências diversas, inclusive sanitárias, saíram-se muito pior do que o esperado no enfrentamento à pandemia em função de escolhas inadequadas, já China e sobretudo Nova Zelândia obtiveram melhores resultados no controle da mesma. Uma das lições já aprendidas com a pandemia em curso é a necessidade de valorizarmos a gestão pública e o tempo de resposta nos critérios de aferição da capacidade instalada para o enfrentamento de crises sanitárias e humanitárias emergenciais. A resposta rápida, consistente e sustentável de lideranças políticas também foi fundamental nos países que apresentaram os melhores resultados no combate à COVID-19.

Embora esperada, a chegada da pandemia à América Latina encontrou um continente enfraquecido pelo modesto crescimento econômico, quando comparado aos demais continentes; seu setor público (saúde, ciência e educação) debilitado pela redução dos investimentos em políticas pública, como consequência das políticas de austeridade fiscal; com maior instabilidade política do que na década anterior; e enfraquecido em seus vínculos regionais pelo esgarçamento de estruturas como a UNASUL (União de Nações do Sul), o Mercosul (Mercado Comum do Sul), a OEA (Organização dos Estados Americanos) e a implementação tímida da CELAC (Comunidade de Estados Latino-Americanos e Caribenhos). Uma justaposição de debilidades se apresenta em vários países da região, onde a escassez de recursos aliada aos conflitos nacionais são potencializados pelas fragilidades dos instrumentos de governança regional, que por sua vez já sofriam os efeitos do enfraquecimento dos instrumentos de governança global, incluindo a própria OMS (Organização Mundial da Saúde).

\section{Oportunidades para a revisão de caminhos}

Mesmo nas grandes catástrofes, o infortúnio nunca é distribuído de forma igual. A prévia, e por vezes secular, acumulação de recursos dota nações e indivíduos de capacidades diferenciadas para o enfrentamento de crises, mesmo quando sobrevêm erros na abordagem inicial dos problemas. Dessa forma, sabemos que a superação da pandemia e a reconquista dos padrões sociais e econômicos mais confortáveis acontecerão de forma desigual.

É preciso que se mobilize nos planos global, regional e nacional os meios para deter o agravamento das desigualdades socioeconômicas - e consequentemente de saúde - que virão como consequência da contração econômica, estimada em 5,3\% para a América Latina, empurrando mais de 30 milhões de habitantes desta região para a pobreza ${ }^{5}$.

Políticas econômicas, sobretudo o modelo de alocação de recursos em relação às áreas que se mostraram essenciais para o enfrentamento deste choque (saúde, ciência e tecnologia, educação e proteção social) devem ser revistas para aumentar a proteção dos países aos choques futuros. A recuperação da empregabilidade necessitará ser feita enquanto se busca mitigar os efeitos da alteração dos padrões tecnológicos na produção, que já tendia ter efeitos perversos sobre a empregabilidade. Economistas da saúde têm defendido que a ativação e priorização de um complexo médico industrial da saúde, adequadamente desenhado e implantado, pode ser parte da solução, trazendo dinamismo econômico e melhorando a capacidade de resposta a problemas sanitários existentes, que prejudicam a população, e a outras epidemias que possivelmente virão 6 .

Por fim, é preciso não se descuidar da dimensão individual em que a vida ao final se realiza, apesar de fortemente influenciada pelos fenômenos mais amplos citados. Para tanto, nos auxilia a perspectiva sociológica proposta por Norbert Elias 7, na qual a interdependência social configura uma economia dos afetos, articulando as dimensões coletiva e individual. Uma abordagem que nos ajuda a desenvolver uma visão mais integrada dos fenômenos, nos anos em que convivemos com a COVID-19. 


\section{Colaboradores}

N. T. Lima propôs e redigiu o núcleo central do texto. P. M. Buss contribuiu na redação e revisão do texto. R. Paes-Sousa contribuiu na redação e organizou a edição final do texto.

\section{Informações adicionais}

ORCID: Nísia Trindade Lima (0000-0002-24947077); Paulo Marchiori Buss (0000-0002-99449195); Rômulo Paes-Sousa (0000-0002-3384-6657).

\section{Agradecimentos}

Os autores agradecem a Guilherme Franco Netto pelo incentivo em publicar este artigo, que é produto do debate realizado entre os mesmos no Ciclo de Estudos - Saúde e Ambiente, Saúde do Trabalhador e Emergência em Saúde - COVID-19, organizado e mediado por Franco Netto.

\section{Referências}

1. Krause RM. Foreword. In: Morse SS, editor. Emerging viruses. Oxford/New York: Oxford University Press; 1993. p. xvii-xix.

2. Fidler D. SARS, governance and the globalization of disease. New York: Palgrave Macmillan; 2004.

3. Roth P. Nêmesis. São Paulo: Companhia das Letras; 2011

4. Cameron EE, Nuzzo JB, Bell JA. Global health security index: building collective action and accountability. Baltimore: Johns Hopkins, Bloomberg School of Public Health; 2019.

5. Comisión Económica para América Latina y el Caribe. Informe especial COVID-19 no 2: dimensionar los efectos del COVID-19 para pensar en la reactivación. https://repositorio. cepal.org/bitstream/handle/11362/45445/4/ S2000286_es.pdf (acessado em 16/Jun/2020).

6. Gadelha C. O Complexo Econômico-Industrial da Saúde no Brasil hoje. Série especial FES-Brasil; 2020. https://www.nexojor nal.com.br/ensaio/debate/2020/O-Comple xo-Econ\%C3\%B 4mico-Industrial-da-Sa\% C3\%BAde-no-Brasil-hoje (acessado em 16/Jun/ 2020).

7. Elias N. O processo civilizador: uma história dos costumes. Rio de Janeiro: Jorge Zahar; 1994. 